\title{
ON-TREATMENT PLATELET REACTIVITY IN THE ERA OF NEW ADP RECEPTOR BLOCKERS: DATA FROM A REAL-WORLD CLINICAL PRACTICE
}

\author{
Skornova I, ${ }^{1}$ Samos M, ${ }^{2}$ Simonova R, ${ }^{1}$ Zolkova J, ${ }^{1}$ Stanciakova L, ${ }^{1}$ Vadelová L, ${ }^{1}$ Bolek T, ${ }^{2}$ \\ Urban L, ${ }^{2}$ Kovar F, ${ }^{2}$ Stasko J, ${ }^{1}$ Galajda P, ${ }^{2}$ Kubisz $\mathrm{P},{ }^{1}$ Mokan M. ${ }^{2}$
}

${ }^{1}$ National Centre of Hemostasis and Thrombosis, Department of Hematology and Blood Transfusion, Jessenius Faculty of Medicine in Martin, Comenius University in Bratislava, Martin, Slovak Republic ${ }^{2}$ Department of Internal Medicine I, Jessenius Faculty of Medicine in Martin, Comenius University in Bratislava, Martin, Slovak Republic

\section{A bstract}

Objectives: Several studies have questioned the need for platelet function testing in patients treated with new $\mathrm{ADP}$ receptor blockers (ADPRB). The aim of this study was to evaluate the prevalence of high on-treatment platelet reactivity (HTPR) among acute ST-elevation myocardial infarction (STEMI) patients treated with newer ADPRB.

Methods: A prospective study enrolling 44 acute previously ADPRB naive STEMI patients (31 men, 13 women) undergoing primary percutaneous coronary intervention (pPCI) was performed. Among the studied population 23 patients received prasugrel and 21 patients received ticagrelor. Antiplatelet response was tested with light transmission aggregometry (LTA) and vasodilator-stimulated phosphoprotein phosphorylation (VASP-P) flow cytometry assay. Samples were taken prior to coronary angiography (sample 1) and on the day after this procedure (sample 2).

Results: The mean platelet aggregation after induction with ADP was $51.7 \pm 24.8 \%$ in sample 1 and $25.3 \pm 20.1 \%$ in sample 2. An examination of VASP-P showed a mean platelet reactivity index of $56.8 \pm 25.7 \%$ in sample 1 and $23.8 \pm 23.1 \%$ in sample 2, respectively. The study identified $11.4 \%$ of patients in sample 2 as ADP receptor blocker non-responders. No significant differences were found between prasugrel-treated to ticagrelor-treated patients.

Conclusions: This pilot study demonstrated HTPR among acute STEMI patients treated with newer ADPRB.

Key words: High on-treatment platelet reactivity; tailored antiplatelet therapy; prasugrel; ticagrelor; acute myocardial infarction

\section{INTRODUCTION}

Clopidogrel high on-treatment platelet reactivity (HTPR) or "clopidogrel resistance" has become an important clinical problem and is associated with adverse ischemic events including stent thrombosis [1]. Clopidogrel HTPR can be effectively identified with various platelet function tests [2] and represents the major reason for the introduction of new ADP receptor blockers such as prasugrel and ticagrelor. These agents offer a more potent, consistent, and predictable inhibition of platelets compared to clopidogrel. The superiority of new ADP receptor blockers over clopidogrel was recently proven in the meta-analysis of 5,395 patients from 29 studies published by Lhermusier et al. [3]. Moreover, patients with clopidogrel HTPR might profit from tailored intensified antiplatelet therapy [4]. Nevertheless, there is a question about the need for platelet function testing in patients treated with new ADP receptor blockers. In fact, since these agents achieve more potent platelet inhibition, platelet function testing might not bring additional benefits. The aim of this study was to evaluate the prevalence of HTPR among acute ST-elevation myocardial infarction (STEMI) patients treated with newer ADP receptor blockers in day-to-day, real-world clinical practice.

Address for correspondence:

Matej Samoš, M.D. PhD., Department of Internal Medicine I, Jessenius Faculty of Medicine in Martin, Comenius University in Bratislava, Kollarova 2, 03659 Martin, Slovak Republic;

e-mail: matej.samos@gmail.com; phone: +421 907612 943, +421 434203820 


\section{METHODS}

\section{Study design and patient population}

A single centre preliminary prospective study with observational design was performed. The study group consisted of 44 acute STEMI patients (31 men, 13 women, mean age: 65, the youngest patient was 41-year old and the oldest was 83-year old undergoing urgent coronary angiography and the primary percutaneous coronary intervention (pPCI) of a culprit coronary lesion (Table 1). Patients with multi-vessel coronary disease planned for surgical revascularization, patients treated only conservatively, and hemodynamically unstable patients (i.e., patients in Killip class IV), as well as patients with hypertensive crisis, kidney and liver failures were excluded from the study. All patients were treated with aspirin (loading dose of 200 - $400 \mathrm{mg}$ followed by a daily maintenance dose of $100 \mathrm{mg}$ ) and newer ADP receptor blockers: prasugrel (loading dose of $60 \mathrm{mg}$ followed by a maintenance dose of $10 \mathrm{mg} /$ daily) was given to 23 patients and ticagrelor (loading dose of $180 \mathrm{mg}$ followed by a maintenance dose of $90 \mathrm{mg} /$ twice daily) was given to 21 patients. All of the patients were administered weight - adjusted unfractionated heparin therapy (100 IU $/ \mathrm{kg}$ intravenously) prior to $\mathrm{pPCI}$ in order to prevent periprocedural thrombosis. No other antiplatelet or anticoagulant therapy was administrated. In addition, none of these patients was treated with morphine, omeprazole, or another agent which potentially interacts with ADP receptor blockers pharmacokinetics. The decision on ADP receptor blocker therapy strategy (prasugrel vs. ticagrelor) was made by the physician who performed the diagnostic ECG record (General Practitioner, Cardiologist, Emergency Department physician, etc.) prior to admission for coronary angiography. All of the patients were ADP receptor blocker naive at the time of admission. The drug compliance was carefully monitored by a healthcare professional who supervised all antiplatelet drug administration. Venous blood samples were taken after obtaining informed consents from all patients enrolled in this study in order to assess on-treatment platelet reactivity using selected platelet function tests.

Table 1. Demographic data and concomitant medication in studied acute STEMI patients

\begin{tabular}{|c|c|c|c|}
\hline \multicolumn{4}{|c|}{ Studied patient population } \\
\hline Number of patients (men/women) & $44(31 / 13)$ & Stroke & $5.3 \%$ \\
\hline Age & $65(41-83)$ & Beta blockers & $97.4 \%$ \\
\hline Arterial hypertension & $73.7 \%$ & ACE inhibitors or AT1 blockers & $71.1 \%$ \\
\hline Type 2 Diabetes (T2D) & $28.9 \%$ & Statins & $100 \%$ \\
\hline T2D duration (years) & 16.5 & Diuretics & $26.3 \%$ \\
\hline Dyslipidaemia & $63.2 \%$ & Calcium channel blockers & $18.4 \%$ \\
\hline Smoking & $34.2 \%$ & Aspirin & $100 \%$ \\
\hline Obesity & $39.5 \%$ & Ticagrelor & $47.7 \%$ \\
\hline BMI (kg/m $\left.{ }^{2}\right)$ & $28.7 \pm 3.1$ & Prasugrel & $52.3 \%$ \\
\hline
\end{tabular}

\section{Blood sampling and platelet function testing}

Blood samples were taken using 3.8\% citrate vacutainer blood collection tubes and analyzed within 2 hours. The samples were taken in the following time intervals: 
Sample 1 - upon the patient's arrival at the cath laboratory; this sample aimed to test the efficacy of the ADP receptor blocker given in loading doses prior to the urgent coronary angiography and pPCI of the coronary lesion.

Sample 2 - one hour after the administration of the first ADP receptor blocker maintenance dose; this sample aimed to test the efficacy of the maintenance dosage of the in-hospital ADP receptor blocker therapy.

Platelet reactivity was tested using light transmission aggregometry (LTA) with a specific inducer (ADP) and vasodilator - stimulated phosphoprotein phosphorylation (VASP-P) flow cytometry assay.

Light transmission aggregometry (LTA): this method represents the "gold standard" of platelet function testing. ADP (10 umol/l) was used as a specific inducer for ADP receptor blocker efficacy testing. LTA was examined by the Chrono - Log model 700 (Chronolog Corporation, Havertown, PA, USA). Platelet aggregability was assessed on the basis of the change in plasma turbidity after the addition of the specific inducer. Residual platelet aggregability $>50 \%$ after the addition of ADP was considered to be HTPR.

VASP-P flow cytometry assay: in this analysis we used PLT VASP/P2Y12 assay kits (Diagnostica Stago, France). A sample of citrate blood was incubated with prostaglandin E1 (PGE1) and PGE1 + ADP (activated platelets). After cellular permeabilization by nonionic detergent, VASP-P is labeled by indirect no-wash immunofluorescence using a specific monoclonal antibody. Dual color flow cytometry analysis then allowed the comparison of the 2 tested conditions. The analysis was carried out on a FACSCalibur flow cytometer (BD Biosciences, San Jose, California). In the final step the platelet reactivity index (PRI) was calculated using corrected mean VASP fluorescence intensities (MFIc) in the presence of PGE1 alone (resting platelets) or PGE1 + ADP simultaneously (activated platelets). The index represented the ratio of activated/resting platelets and was calculated according to the following equation:

$$
\mathrm{PRI}=\frac{M F I c^{P G E 1}-M F I c^{[P G E 1+A D P]}}{M F I c^{P G E 1}} \chi 100
$$

The resulting value described PRI to ADP treatment in a range of $0 \%$ to $100 \%$. Values of PRI above $50 \%$ were considered as determinant of HTPR and an inadequate response to treatment.

\section{Statistical analysis}

The data were tested for normality with the Shapiro - Walk test. Normally distributed continuous or interval-scaled variables are presented as mean \pm standard deviation (SD); otherwise median (M) and quartile ranges from the lower quartile to the upper quartile were used. Group effects were tested with a t-test in the case of normally distributed data or with the Mann-Whitney U test when data distribution was asymmetrical. Differences between proportions were tested with binominal tests. Categorical variables grouped in 2-way contingency tables were analyzed using chi-square tests. The significance of $p<0.05$ was considered as a criterion for comparison between data sets with equal and unequal variances. The statistical analysis was performed by Statistical v. 7.0 (Stat Soft Inc., Dell Software, and Tulsa, Oklahoma, USA).

\section{RESULTS}

The time interval from ADP receptor blocker loading dose administration to the collection of sample 1 and sample 2 was $1.5 \pm 0.7$ hours and $20.7 \pm 2.3$ hours, respectively. The mean platelet aggregation after induction with ADP was $51.7 \pm 24.8 \%$ in sample 1 and 25.3 $\pm 20.1 \%$ in sample 2. Examination of VASP-P showed a mean PRI of $56.8 \pm 25.7 \%$ in sample 1 and a mean PRI of $23.8 \pm 23.1 \%$ in sample 2 . In the analysis of ADP receptor blocker 
non-responders $52.3 \%$ of patients (23) were identified as ADP receptor blocker non-responders in sample 1 and $11.4 \%$ of patients (5) were ADP receptor blocker non-responders in sample 2.

Subsequently, an analysis of prasugrel-treated and ticagrelor-treated patients (Table 2) was performed. The time interval from ADP receptor blocker loading dose administration to the collection of blood samples did not differ significantly in prasugrel- and ticagrelor-treated patients (sample 1: $1.6 \pm 0.7$ hours vs. $1.4 \pm 0.6$ hours, $p=0.19$; sample 2: $20.4 \pm 2.6$ hours vs. $21.0 \pm 2.0$ hours, $\mathrm{p}=0.41$ ). No significant differences were found in ADP induced platelet reactivity among prasugrel- and ticagrelor-treated patients in sample 1 or in sample 2 (sample 1: $43.0 \pm 20.0 \%$ vs. $61.2 \pm 26.4 \%, p=0.06$; sample 2: $22.4 \pm 13.6 \%$ vs. $28.8 \pm 25.8 \%, p=0.37)$. Similarly, no significant differences were found in the PRI of VASP-P in sample 1 (58.1 $\pm 28.7 \%$ in prasugrel-treated patients vs. $55.4 \pm 23.1 \%$ in ticagrelor-treated patients, respectively, $p=0.77$ ), or in sample 2 $(22.8 \pm 21.9 \%$ in prasugrel-treated patients vs. $24.8 \pm 25.0 \%$ in ticagrelor-treated patients, respectively, $\mathrm{p}=0.81$ ). Comparing prasugrel-treated and ticagrelor-treated patients no difference was found in the prevalence of ADP receptor blocker non-responders in sample 1 (60.9\% of prasugrel-treated patients vs. $42.9 \%$ of ticagrelor-treated patients, $\mathrm{p}=0.24)$, or in sample $2(8.7 \%$ of prasugrel-treated patients vs. $14.3 \%$ of ticagrelor-treated patients, $\mathrm{p}=0.57$ ).

Table 2. On-treatment platelet reactivity, and prevalence of ADP receptor blocker non-responders comparing prasugrel- and ticagrelor-treated patients with acute STEMI.

\begin{tabular}{|c|c|c|c|c|}
\hline \multicolumn{2}{|c|}{$\begin{array}{c}\text { On-treatment platelet reactivity } \\
\text { LTA with ADP induction } \\
(\%)\end{array}$} & $\begin{array}{c}\text { Prasugrel-treated } \\
\text { patients }\end{array}$ & $\begin{array}{c}\text { Ticagrelor-treated } \\
\text { patients }\end{array}$ & $\begin{array}{c}\text { Significance } \\
\text { (p value) }\end{array}$ \\
\cline { 2 - 5 } & Sample 2 & $43.0 \pm 20.0$ & $61.2 \pm 26.4$ & 0.06 \\
\hline $\begin{array}{c}\text { PRI of VASP } \\
\text { phosphorylation (\%) }\end{array}$ & Sample 1 & $58.1 \pm 28.7$ & $55.4 \pm 23.1$ & 0.37 \\
\cline { 2 - 5 } & Sample 2 & $22.8 \pm 21.9$ & $24.8 \pm 25.0$ & 0.81 \\
\hline $\begin{array}{c}\text { ADP receptor blocker non-responders } \\
(\%)\end{array}$ & $\begin{array}{c}\text { Prasugrel-treated } \\
\text { patients }\end{array}$ & $\begin{array}{c}\text { Ticagrelor-treated } \\
\text { patients }\end{array}$ & $\begin{array}{c}\text { Significance } \\
\text { (p value) }\end{array}$ \\
\hline \multirow{2}{*}{$\begin{array}{c}\text { ADP receptor blocker } \\
\text { non-responders }\end{array}$} & Sample 1 & 60.9 & 42.9 & 0.24 \\
\cline { 2 - 5 } & Sample 2 & 8.7 & 14.3 & 0.57 \\
\hline
\end{tabular}

\section{DISCUSSION}

Prasugrel and ticagrelor, new ADP receptor blockers, achieve more potent and predictable antiplatelet effect compared to clopidogrel, which was previously confirmed in the TRITON-TIMI 38 [5] and PLATO [6] trial, respectively. Furthermore, as reported previously, these agents might effectively overcome clopidogrel HTPR [4]. In fact, since they cause more potent platelet inhibition, the platelet function testing in patients on prasugrel or ticagrelor might not bring additional benefits. Moreover, the platelet testing might be connected with additional costs (need for blood sampling, expensive laboratory analysis, etc.). From this point of view the more frequent use of new ADP receptor blockers (with predictable and consistent antiplatelet effect) could probably reduce the future need for monitoring antiplatelet therapy. 
On the other hand, this preliminary prospective study demonstrated HTPR among acute STEMI patients treated with newer ADP receptor blockers. In fact, the higher prevalence of ADP receptor blocker non-responders in sample 1 could be due to the relatively short time interval from ADP receptor blocker loading dosing to blood sampling (1.5 \pm 0.7 hours); particularly in the setting of acute STEMI. Nevertheless, this study showed that $11.4 \%$ of the patients remained ADP receptor blocker non-responders despite standard ADP receptor blocker doses even in a sample taken more than 20 hours from ADP receptor blocker loading dosing. HTPR was found both in prasugrel- and ticagrelor-treated patients. Similarly, Cayla et al. [7] showed that $6.7 \%$ of prasugrel treated post-PCI patients did not respond adequately even in blood samples taken 2 to 4 weeks after the initiation of prasugrel therapy. The high prevalence (25.2\%) of prasugrel non-responders among ACS patients treated with PCI was consistently demonstrated in the study performed by Bonello et al. [8]. Moreover, HTPR in this study was associated with an increased risk of MACE after PCI. In light of these data the real prevalence of HTPR on new ADP receptor blockers might be higher than is usually considered. Clopidogrel HTPR seems to be a complex problem [9]; on the other hand, HTPR on new ADP receptor blockers hasn't been satisfactorily studied and explained. In our study, drug under-dosing, the short time interval from drug administration to blood sampling (HTPR was demonstrated in samples taken more than 20 hours from administration of loafing doses) and drug non-compliance are probably not responsible for HTPR. However, more studies are needed in order to clarify this phenomenon.

Recently, several studies have attempted to answer the question of whether HTPR is a modifiable factor. The GRAVITAS study [10] which addressed the issue of overcoming HTPR with modified clopidogrel doses guided by platelet function testing brought negative results. Nevertheless, a study with observational design [4] or registry analysis [11] suggested that tailored ADP receptor blocker therapy might be beneficial for selected patients. The analysis of IDEAL-PCI registry [11] enrolling 1008 consecutive post-PCI patients demonstrated that the individualization of dual antiplatelet therapy with platelet function testing reduces early thrombotic events post-PCI without increasing bleeding. Therefore, the question: "Do we need to monitor antiplatelet therapy in the era of new ADP receptor blockers?" remains unanswered and further studies aiming at the detection of the real prevalence of HTPR in prasugrel and ticagrelor treated patients and its impact on clinical outcome are definitely needed in order to clarify this matter. Until those studies are performed the monitoring of antiplatelet therapy may still play an important role in clinical practice.

There were some important limitations to our analysis. First, this study had a prospective observational design and not a randomized double blinded one. Therefore, the data obtained in this study do not have the evidential strength of data from a randomized double blinded trial. Second, the low sample size might be a limitation. A relatively small patient sample cannot guarantee significant power. Finally, the drug compliance was not proven by laboratory testing (measurement of ADP receptor blockers metabolite, etc.). Although drug compliance in this study was carefully monitored by a healthcare professional who supervised all antiplatelet drug administrations the exact confirmation of drug compliance by laboratory assessment is missing. The results of this study should be confirmed in large, similarly designed, randomized trials.

\section{CONCLUSION}

This preliminary study demonstrated HTPR among previously ADP receptor blocker naïve patients with first acute STEMI treated with newer ADP receptor blockers. Thus, the role of monitoring $\mathrm{ADP}$ receptor blocker therapy even in the era of new $\mathrm{ADP}$ receptor blockers requires more extensive study. 


\section{REFERENCES}

[1] Angiolillo DJ, Fernandez-Ortiz A, Bernardo E, Alfonso F, Macaya C, Bass TA, Costa MA. Variability in individual responsiveness to clopidogrel: clinical implications, management, and future perspectives. J Am Coll Cardiol 2007; 49: 1505 - 1516

[2] Fedor M, Samoš M, Šimonová R., et al. Monitoring the Efficacy of ADP Inhibitor Treatment in Patients With Acute STEMI Post-PCI by VASP-P Flow Cytometry Assay. Clin Appl Thromb Hemost. 2015; $21: 334-338$.

[3] Lhermusier T, Lipinski MJ, Tantry US, Escarcega RO, Baker N, Bliden KP et al. Meta-analysis of direct and indirect comparison of ticagrelor and prasugrel effects on platelet reactivity. Am $\mathrm{J}$ Cardiol 2015; 115: 716 - 723.

[4] Paarup Dridi N, Johansson PI, Lønborg JT, et al. Tailored antiplatelet therapy to improve prognosis in patients exhibiting clopidogrel low-response prior to percutaneous coronary intervention for stable angina or non-ST elevation acute coronary syndrome. Platelets. 2014; 28: 1 - 9.

[5] Wiviott S, Braunwald E, McCabe C, et al. Prasugrel versus clopidogrel in patients with acute coronary syndromes. N Engl J Med 2007; 357: 2001-2015

[6] Wallentin L, Becker RC, Budaj A, et al. Ticagrelor versus clopidogrel in patients with acute coronary syndromes. N Engl J Med 2009; 361: 1045 - 1057.

[7] Cayla G, Cuisset T, Silvain J, et al. Prasugrel monitoring and bleeding in real world patients. Am J Cardiol 2013; 111: 38 - 44.

[8] Bonello L, Pansieri M, Mancini J, et al. High on-treatment platelet reactivity after prasugrel loading dose and cardiovascular events after percutaneous coronary intervention in acute coronary syndromes. J Am Coll Cardiol 2011; 58: 467 - 473.

[9] Roberts DI, Nawarskas JJ. Treatment options for patients with poor clopidogrel response. Cardiol Rev 2013; 21: 309 - 317.

[10] Price MJ, Berger PB, Teirstein PS, et al. Standard- vs high-dose clopidogrel based on platelet function testing after percutaneous coronary intervention: the GRAVITAS randomized trial. JAMA. 2011; 305: 1097 - 1105.

[11] Christ G, Siller-Matula JM, Francesconi M, et al. Individualising dual antiplatelet therapy after percutaneous coronary intervention: the IDEAL-PCI registry. BMJ Open 2014; 4:e005781.

Acknowledgments: This study was supported by the APVV project (Slovak Research and Development Agency) 16-0020. The authors would like to thank Mr. Paul McCullough for proofreading.

Received: September,5,2018

Accepted: September,30,2018 